notice on the Hydrographic Department which appeared in NATURE, vol, xxii. p. 86, on the grounds advanced by him in the first paragraph of his letter.

Our readers will scarcely receive Lieut. Temple's statement that that department has deliberately given dangerous publicity to errors. This would be contrary to the traditions, and certainly to the interests, of any public office connected with the practical and working world. But however this may be, is not the Hy. drographic Department pursuing a prudent course in causing a revision to be made of Lieut. Temple's compilation by another authority? In the interests of navigation we think it is ; for on a great stretch of coast like Norway, which, from its sinuous and broken character, can be reckoned by thousands of miles of sea-board, it is clearly unadvisable that dependence should be entirely placed on the efforts of one individual.

We are the more confirmed in this belief from a significant letter which lately appeared in the Shipping and Mercantile Gazette and in the Daily News from the Royal Norwegian Geographical Survey Office, dated Christiania, the 16th inst., written, as the writer alleges, "in order to correct the erroneous statements contained in Mr. Temple's paper (read at the Society of Arts) respecting the charts and descriptions of the Norwegian coast now existing."-ED.]

\section{Curious Electric Phenomenon}

AT about 4.30 p.m. this day a severe thunderstorm with a deluge of rain came up from the north-west and lasted about an hour. At 5.30 my wife was standing at the window watching the receding storm, which still raged in the south, just over Leicester, when she observed, immediately after a double flash of lightning, what seemed like a falling star, or a fireball from a rocket, drop out of the black cloud about $25^{\circ}$ above the horizon, and descend perpendicularly till lost behind a belt of trees. The same phenomenon was repeated at least a dozen times in about fifteen minutes, the lightning flashes following each other very rapidly and the thunder consisting of short and sharp reports. After nearly every flash a fireball descended. These balls appeared to be about one-fifth or one-sixth the diameter of the full moon, blunt and rounded at the bottom, drawn out into a tail above, and leaving a train of light behind them. Their colour was mostly whitish, but one was distinctly pink, and the course of one was sharply zig-zagged. 'They fell at a rate certainly not greater than that of an ordinary shooting star. I have never witnessed a phenomenon of this kind myself, but my wife is a good observer, and I can vouch for the trustworthiness of her report.

Birstal Hill, near Leicester, June 22

F. T. Motт

\section{Meteor}

ON Friday, June Ir, at 8.5 p.m., while the sun was still shining, I saw due east as near as I could judge, and about $30^{\circ}$ above the horizon, a bright white meteor pass across about $10^{\circ}$ or $12^{\circ}$ from right to left with a slight downward course. Two or three hours later I saw a small one take a parallel course, but the other side the zenith.

Coventry, June 14

W. ODELL

\section{Minerva Ornaments}

DURING a recent visit to England I spent a considerahle time in the Museum at South Kensington, and Dr. Schliemann's collection of antiquities was one of the objects in that museum which I was most desirous to see.

I should like to call attention to one point in regard to this collection of relics. Among others I saw a number of flat rounded pebbles, which, by chipping at the middle on both edges, have been brought into something like the shape of an hour-glass. These are marked "Minerva Ornaments." There are several other relics, the titles on which seemed to me to be, speaking within bounds, somewhat imaginative; such, for example, as the small pieces of gold plate on the $\pi \lambda \epsilon \kappa \tau \dot{\eta} \dot{\alpha} \nu \alpha \delta \delta^{\prime} \sigma \mu \eta$, or headdress, where Dr. Schliemann sees the owl's head and two large eyes, "which cannot be mistaken"; but to name these flat pebbles "Minerva Ornaments" seems to trespass not a little beyond the due limits of the imagination when applied to science.

Stones of precisely the same shape and size, and cut in the same way, are common in this country, where Minerva was " an unknown goddess" before the arrival of the Christians, They are picked up on the banks of the rivers, and when placed in collections are ticketed "net-sinkers." I cannot doubt that Dr. Schliemann's "Minerva Ornaments" are only Trojan net-sinkers formed as those of the aboriginal inhabitants of this country, because the savage mind seems to have run in the same channel all over the world.

Antioch College, Ohio

E. W. Claypole

\section{A Snake in Kensington Gardens}

I wAS considerably surprised this evening at finding the lifeless body of a snake about one hundred yards to the south-east of Kensington Palace. A policeman informed me that he had killed it there last Thursday as it was rapidly moving over the ground. The head and neck had been utterly destroyed, most likely by stampings of the policeman's foot, but the remainder of the body was perfect. In length it was about twenty inches, the body, from the thickness of a little finger, gently tapering to a tail ending in a fine point. Regular scales, brownish-black in colnur, clothed the back, the scales along the sides being yellowish-green. A distinct fringe, or prolonged fin, stiffly standing erect. of about one-quarter of an inch in height, ran down the centre of the back, is colour the same as the rest of the body in that region. I trust this description may enable some of your readers learned in snakes to identify the species. Then I would ask, Is this animal a native of these parts, or had it been introduced, or had this specimen most likely escaped from captivity to meet with its untimely end ?

I I, Sheffield Gardens, Kensington, W. J. HARRIS STONE

\section{THREE YEARS' EXPERIMENTING IN MENSURATIONAL SPECTROSCOPY}

\section{BY A NEW HAND THEREAT}

$T^{T}$ was in 1876 that the experimenter, ${ }^{1}$ of whom the following notes have been requested, clearly perceiving that it would not do any longer, even in his private work, to be content with merely a little directvision, ready-made, purchased, spectroscope and the few scale points offered by reference to lamp-flame lines-set about making up a tolerably large spectroscopic instrument to satisfy his own ideas, wants, and aims.

Now the leading desire with him herein, was, in suitable return for H.M. Government having then recently changed the locality of his official residence from a low, sunk position, where and whence little but other houses could be seen, to an elevated site half-way up the northern side of the Calton Hill, commanding an excellent view of the northern, north-eastern, and north-western horizons, togetlier with the best and brightest parts of almost all auroral displays, whenever they occurred-it was his desire, as a decorous and appropriate tribute, to render some respectable spectroscopic account (over and above anything that the Royal Observatory, Edinburgh, and its more purely astronomical instruments could do) of those sometimes nocturnally lumincus, but generally fitful, evanescent, and not yet fully explained, phenomena of the skies, the Aurora Polares.

To this end the nascent spectroscope, mounted before a window in an upper chamber, assumed the form of a large flat telescopic box, almost five feet long, two broad, balf a foot deep, supported on a stout alt-azimuth stand, with powerful screw motions. The box carried a gathering telescope in front, whose objective, as well as those of the internal collimator and inspecting telescope, were, like those of a "night-glass," large, i.e., 2.2 inches in diameter; and short, i.e., 17 inches, in focal length. An extensive and easily read scale for any prism's minimum deviation positions, and a long, but very easily worked, micrometerscrew motion for the telescope eye-piece were supplied, also an illuminated pointer. An electric reference spectrum of hydrogen lines above and below the fiducial central zone of the field of view was caused to be ever

\footnotetext{
x Prof. Piazzi Smyth, Astronomer-Royal for Scotland.
} 
available; the slit, though 4 feet distant, was made capable of being adjusted from the observer's chair; a variety of prisms both simple and compound, with deviations from $0^{\circ}$ to $45^{\circ}$, and dispersions from $0^{\circ} .5$ to $14^{\circ}$ between $A$ and $H$ solar, but all of large size, and capable of being used in quick succession at pleasure, were added; with further arrangements for bringing into central view and correct measure, many other natural spectroscopic milestone lines, both with blowpipe-flame and induction-spark.

Thus far the instrument had been constructed, step by step to a series of orders, chiefly by M. Salleron, of 24 , Rue Pavée au Marais, Paris, and it was ready in the beginning of 1877 for any aurora that should display itself in the north-north-western parts of the sky; but no auroras came, nor have any appeared up to the present time, February, 1880. But the instrument has not been idle. Its general material, wood, allowed it to be cut into and altered for any experiment, educational or otherwise; Mr. Adam Hilger, of 192, Tottenham Court Road, furnished it with a train of compound prisms raising its dispersion powers to $33^{\circ} \mathrm{A}$ to $\mathrm{H}$, with improved Huyghenian rockcrystal eye-pieces and a spectrum-illuminated pointer of a remarkable kind for the purity of the colours successively imparted; until, though large parts of the apparatus were still rough, it had become, on the whole, an essentially safe instrument for spectroscoping numerically anything within its powers to spectroscope at all, and for looking into any such subject in a variety of different ways, and to different degrees as to definition, illumination, dispersion, and magnifying ; thereby imparting considerable confidence in its final results: and this is the chief reason for saying so much at starting on the mere means employed.

Colours and Absorption Spectra.-The first series of observations with this new instrument was of a very simple kind as to the smallness of dispersion employed, and on an often discussed subject, viz., the colours both of the spectrum and of various coloured media, solid as well as fluid. These observations were printed by the Royal Society, Edinburgh, in vol. xxyiii. of their Transactions (1 878), in a paper extending through sixty-four pages and illustrated with three plates; one of them containing twenty-five different colours, viewed under seven different gradations. Though much of the subject matter of this paper could only be a confirmation, perhaps strengthening, of many previous workings by others in the same directions; yet the following points, more or less new, were also clearly established; as--

I. Colour bands, and bounding edges of coloured regions in the spcctrum, are not fixed in spectral place as both Fraunhofer lines and luminous lines of gases so eminently are, but have a positive power of locomotion, within certain limits, according to intensity of itlumination and depth of colouring matter. Witness especially the march of the whole red band of light, with successively increased depths of solution, over, and past, the black Fraunhofer line, both found on this occasion in oxalate of chromium and potash dissolved in water, and proved to be as fixed as any other Fraunhofer line in all spectroscopy.

2. Amongst colours the same to the eye, a physical difference still more important than colour was ascertained to exist, accordingly as their transmitted spectra formed, either one central beam, or two widely separated beams in spectral place. So that one green glass exhibited only the green region of the spectrum; while another glass, of different chemical coloration, but equally green to the eye, shone chiefly in setting forth the ultra-red regions of the spectrum at one end, and some of the blue at the other, but extinguished strangely the yellow, citron, green, and all that might have been expected a priori to have been well rendered by it.

3. Amongst these double-beam colours, of which cobalt- blue glass is an old example, well known from the times of Sir David Brewster downwards, a far more powerful case was met with in Judson's green dye of the aniline series; and by merely looking through a film of that (without any prismatic or spectroscopic assistance) it was shown to be possible to detect copper and arsenic greens among vegetable green dyes in papers and muslins; with all the facility too, of seeing the former become blue or black, while the latter became red, and sometimes gloriously so.

4. While the green of vegetation was in every case, both abroad and at home, together with its yellows, its blue as in litmus dye, and some of its browns, turned into crimson or scarlet-the green of shallow sea-water, as in the mouth of the Tagus, and the deep blue of the ocean, as in the Bay of Biscay, were both of them totally unaffected; but brown oars dipped in the act of rowing into the former, in itself unimpressible, green water, came up blood-red at every stroke; and brown seaweed floating in the blue Bay, appeared of a richer scarlet than any coral. These scenes too were all the more brilliant and life-like to the observer, though looking through something like a black ink-bottle, from the tendency ascertained of two superposed films of any of these double-beam colours, when differently illuminated (the one looked at having to be more strongly illuminated than the one looked through), to produce light, rather than double dark, in and about the $F$ region of the spectrum ; thus recalling a remarkable feature established by the late esteemed Prof. Clerk Maxwell, in his researches on colour-blindness.

Rain-band Spectroscopy.-The next subject on which the experimenter published (both in the Journal of the Meteorological Society of Scotland and in the fourteenth volume of the "Edinburgh Astronomical Observations") was the power of the spectroscope to foretell rain. This subject had been much studied by him already in various countries and climates with pocket spectroscopes, but assumed a far firmer character when their indications could be tested by the spectroscopic machine above described.

Every spectroscopist knows how rich in black lines and grey bands is the red-end of the spectrum of the sky; especially towards sunset, and near the horizon. $M$. Ângström had moreover already taught that some of those lincs or bands were due to watery vapour, and others to dry gas, in the earth's atmosphere; while $M$. Janssen had minutely identified the components of the former as being of such an origin, by comparing them with the absorption lines in a long tube of high-pressure steam. The Edinburgh experimenter therefore started with much prepared to his hand, when seeking to obtain a practical use for meteorology out of such observations ; ard his further steps were these:-

I. He ascertained by many months of continued daily experience that the lines attributed to watery vapour in the spectrum of the sky, though formed by that vapour when in the state of a transparent, invisible gas, increased in their intensity of darkness, other things being the samc, according to the quantity of such vapour present in the atmosphere. That quantity being independently ascertained for the time by reference to wet and dry bulb thermometers and the usual hygrometrical calculations.

2. To keep those "other things the same," and prevent the variations they are only too capable of setting up, from interfering with the one phenomenon now sought after, the experimenter confined his spectroscopic notings of the sky's light to a constant, and that a low, altitude therein; as well as to an hour giving a constant, and not a very low altitude to the sun, and an azimuthal direction considerably distant therefrom. Also to blue sky itself, as seen through openings between clouds, if possible, rather than to any cloud surface, and much rather than to 
any haze, fog, or smoke surface nearer still than the clouds.

3. These precautions being taken, there was no difficulty in recognising, first, during frosty weather, when meteorologists know there is a minimum of moisture in the air, what should be the normal appearance of the dry-gas lines or bands, for they only are then conspicuous, and are chiefly great $\mathrm{B}$, the alpha band between $\mathrm{C}$ and $\mathrm{D}$, and a remarkable band on the green side of the universally known $D$ line of the regular solar spectrum. That band being remarkable, not only for being situated as a dark shade in the otherwise brightest part of the spectrum of daylight, but by being much more dependent than the other dry bands, on the lowness of altitude of the sun at the moment, for its full and darkest development, and thence called in these inquiries "the low-sun band." $N e x t$, in the summer season of the year when the temperature has risen say to $70^{\circ}$, and we know, as per the acknowledged hygrometrical tables, that there is then four times as much, to the eye invisible, moisture in the air, for that reason only, as at $30^{\circ}$ temperature-spectroscop:c observation will show, simultaneously with and in addition to, all the previous dry-gas lines, not only a strong watergas, or vapour, line closely following $\mathrm{C}$, a true sun-line, but a much grander line, double line, or rather band of lines immediately preceding the solar line $\mathrm{D}$; and this particular water-vapour group is in practice the only one of that kind which meteorologists need attend to in their ordinary daily work.

So far indeed we have only got, by its means, a species of thermometer; but if we go on observing day after day in nearly similar summer temperature, and accustom ourselves thereby to the then quality of appearance of that band preceding $\mathrm{D}$-and if on the next day, at the same, or nearly the same, temperature, we should see the band, say twice as dark as on the previous days-then in that excess of darkness it has become "the rain band" sought for. Because that abnormal excess of darkness shows as infallibly as though it were written up in the sky, that there is at that moment far more invisible watery vapour in the upper atmosphere than the air there is capable of holding much longer in suspension, wherefore such extra moisture must very shortly be deposited as rain.

This then is the "rain-band spectroscopy" established by the Edinburgh experimenter; and it may be now successfully practised with the smallest spectroscopes either at home or abroad; when one is travelling as well as when stationary, for it occupies only a moment of time each day, as the merest glance will tell whether the rain-band preceding $\mathrm{D}$ is much stronger or less strong than the normal quantity; and with all the more certainty on account of the low-sun band immediately following $D$ in the spectrum, enabling a differential, as well as an absolute, estimate of darkness to be formed. While in any but very cold and wintry weather, when Nature herself tilts the balance for rainfall by a very small addition to the watery vapour in the air, the spectral indications are easily read off and apprehended. They have also been found as certain at sea, in South Africa, and India, or wherever the system has been carried, as in Great Britain during the best part of its summer season.

If the research be further prosecuted with large dispersions, high magnifying powers, and on the direct light of the sun, the hazy bands above spoken of as existing in the general daylight, are found in the same spectral places, but breaking up into scores and hundreds of fine lines; while the range of visible spectrum then extending from the B limit of the mere sky and indirect sun's light, to great $\mathrm{A}$ and beyond it-the intermediate groups of lines called "little $a$ and its preliminary band" will be found a still more powerful "rain-band" than that near $D$. For though they, little $a$ and its preceding band, are composed of lines vanishingly thin, few and far apart in dry weather and as seen in a high sky, yet their interstices in damp weather become peopled with myriads and myriads of black lines, so as at last, indeed, in a setting sun, to block up the whole space of each group, from one side to the other, solidly ; and then actually to dwarf the almost proverbial spectral colossus "great A," into a mere line comparatively puny and unimportant.

The Red-End of the Solar Spectrum.- "There must surely be some mystery of difficulty," thought the experimenter, "touching the red-end of the spectrum of the high sun, or the able Angström, of Upsala, would not have omitted it in his otherwise grandly perfect normal solar spectrum map; while some points in the Royal Society's Himalayan solar spectra would have been very differently rendered." Now one undoubted obstacle to mapping that part of the spectrum well, is undoubtedly the faintness of its light; wherefore an idea immediately occurred to the new worker that the qualities of his aurora spectroscope were the very desiderata for both the red, the ultra-red, and for everything, in fact, that the very beginning of the solar spectrum has to show beyond, or earlier than, the point where Angström's spectrum commences its admirable delineations with the rudimentary lines of only little $a$ and its preliminary band.

But the summer of 1877 threatening to be hopelessly cloudy in Scotland, the experimenter, after considering the various pros and cons of many southern stations, decided on trying Lisbon, as the place of all others giving the highest summer sun, the best climate, and most social facilities, with least time lost in getting there. And then he further happily experienced, not only that the magnificent steamers of the Pacific Steam Navigation Company of Liverpool, are the most admirable means of accomplishing the ocean transit; but that the directors of that Company are most favourably and liberally inclined to help on any really scientific matter when for the sake of science alone.

Hence it was that in June and July, in Portugal, with his Edinburgh spectroscope and a heliostat of simple construction worked for him by his Wife's hand and eye, the experimenter was enabled to see and map at noonday, and, day after day, in a high sky, free from ordinary telluric effects, all that portion of the solar spectrum outside, or situated preliminarily to, Ångström's shortened beginning; viz., the matchless series of lines that go towards forming the colossal groupings of both great A and its grand preliminary band; then beyond that the very strong line $\mathrm{Y}$ and the groups of finer lines on each side of it ; and beyond that again, near the beginning of all visible spectral light, the strong line $\mathrm{X}$, and certain thinner lines on either side of it.

Photography, as Capt. W. de W. Abney has admirably shown since then, can take account of many more lines still; and some of them so very far away beyond all visible red light, as to remind one of those other lines recorded by Dr. Draper, the elder, in his celebrated Daguerreotype spectrum taken in 1843 , lines which are quite outside the pale of all optical spectra. But the human eye had probably never, up to 1877 , seen more in the "red" than what the Edinburgh experimenter's rough!y built-up aurora spectroscope showed on this occasion: and the whole result, as contributing at last the head-piece required for Angström's normal solar spectrum, was described in the I4th volume of the "Edinburgh Astronomical Observations," published towards the end of the same year 1877 . It was accompanied there by a map, extending from the beginning of all visible light, and including 62 lines up to the groups of little $a$, so correctly represented in themselves by the philosopher of Upsala.

(To be continued.) 